REVIEW

\title{
Role of myocardial perfusion imaging for risk stratification in suspected or known coronary artery disease
}

\author{
N K Sabharwal, A Lahiri
}

Heart 2003;89:1291-1297

Nuclear cardiology is an evolving specialty that has recently benefited from technological and radiopharmaceutical advances. As a result there has been an increase in the accuracy of myocardial perfusion imaging (MPI) with gated single photon emission computed tomography (SPECT) for assessing the diagnosis and prognosis of coronary artery disease. Moreover, ECG gated SPECT allows the simultaneous assessment of both myocardial perfusion and left ventricular function, which provides additional prognostic value. With increasing concern over early detection of coronary artery disease and its effective treatment, myocardial perfusion imaging is ideally placed to provide a full "one stop" functional assessment for any patient, irrespective of their exercise capacity. This applies not only to patients with chest pain but also to those with myocardial infarction, revascularisation, and heart failure, and those being assessed for non-cardiac surgery. The focus of this review is the use of myocardial perfusion imaging in risk stratification for coronary artery disease.

See end of article for authors' affiliations

Correspondence to: Dr Avijit Lahiri, Department of Cardiac Research, Northwick Park Hospital, Watford Road, Harrow, Middlesex HA I 3UJ, UK; nph@ cardiac-research.org

Accepted 19 May 2003
$\mathrm{T}$ he classical hallmark of myocardial ischaemia has been the presence of transient ST segment depression on exercise. The pre-test likelihood of coronary artery disease dictates the sensitivity and specificity of the stress ECG; thus in the presence of a low or intermediate pre-test likelihood of coronary disease the exercise ECG has poor diagnostic accuracy. ${ }^{12}$ In many health care systems, risk stratification of patients with chest pain syndromes is attempted using clinical and ECG evaluation and acute markers of myocardial injury. These are often followed by an exercise ECG if the resting ECG and troponin measurements are unremarkable. For many patients a stress ECG has poor sensitivity and specificity and is therefore unlikely to be the method of ideal choice. ${ }^{3}$ Functional myocardial perfusion imaging (MPI), which provides evidence by directly measuring "total ischaemic burden", is clearly the method of choice in lower and intermediate risk patients. ${ }^{4}$ Worldwide, the uptake of myocardial perfusion is expanding, with increasing interest in the use of MPI as a gatekeeper to coronary angiography. In this review we focus on examining the diagnostic and prognostic value of state of the art myocardial perfusion imaging.
It has taken 25 years to establish the clinical role of MPI using single photon emission computed tomography (SPECT). MPI agents are potential myocardial flow tracers; thus they identify abnormal flow early in the ischaemic cascade, before wall motion abnormality or ECG changes become apparent. The advent of new radioisotopes (technetium-99m agents), advanced dual and triple headed SPECT gamma cameras, diverse pharmacological "stress" agents, newer computer software, and ECG gated SPECT have all come together to make MPI a versatile clinical tool. No less important was the formation of the American Society of Nuclear Cardiology (ASNC) in 1994, and the ensuing requirement for cardiologists in the USA to obtain a licence to carry out and read scans. Approximately 5.64 million myocardial perfusion scans were done in the USA in 2001 (Arlington Medical Resources, 2001).

A commonly used alternative to MPI is the stress echocardiogram. This technique relies on the detection of stress induced wall motion abnormalities. The overall sensitivity is lower than MPI but with a slightly higher specificity. The prognostic value of a normal scan is comparable to that of $\mathrm{MPI}^{5}$; ; however, the technique relies heavily on operator experience, is blighted by poor acoustic windows, and there is a lack of quantitation.

\section{ISOTOPES}

Though thallium-201 was the first radionuclide to be widely used in clinical practice, it was the advent of technetium-99m sestamibi and tomographic imaging (SPECT) with quantitative analysis that provided the thrust for further development. Technetium-99m agents are also better suited for imaging with modern gamma cameras. Table 1 shows the agents currently in use.

\section{STRESS PROTOCOLS}

There is a large body of diagnostic and prognostic data on myocardial perfusion imaging. The data are based on different agents, cameras, stress

Abbreviations: ASNC, American Society of Nuclear Cardiology; CHRISTMAS, carvedilol hibernation reversible ischaemia trial: marker of success; EMPIRE, economics of myocardial perfusion imaging in Europe; END, economics of noninvasive diagnosis; FDG, fluorodeoxyglucose; MPI, myocardial perfusion imaging; $\mathrm{PET}$, positron emission tomography; SPECT, single photon emission computed tomography; SSS, summed stress score 
Table 1 Comparison of different radionuclide agents currently in routine clinical use for myocardial perfusion imaging

\begin{tabular}{|c|c|c|c|c|c|c|}
\hline Radionuclide & Half life & $\begin{array}{l}\text { Activity } \\
\text { administered }\end{array}$ & Effective dose & $\begin{array}{l}\text { Mechanism of } \\
\text { myocardial uptake }\end{array}$ & Redistribution & Comments \\
\hline${ }^{201} \mathrm{Tl}$ & 72 hours & $60-80 \mathrm{MBq}$ & $15-20 \mathrm{mSv}$ & $\begin{array}{l}\text { ATPase- } \mathrm{K}^{+} \text {myocyte cell } \\
\text { membrane integrity } \\
\text { required }\end{array}$ & Redistributes & $\begin{array}{l}\text { Poor quality images; difficult to gate. Prognostic } \\
\text { data available; redistribution advantageous for } \\
\text { viability detection }\end{array}$ \\
\hline${ }^{99 \mathrm{~m} T c-s e s t a m i b i}$ & 6 hours & $800 \mathrm{MBq}$ & $8 \mathrm{mSv}$ & Myocyte mitochondria & Minimal & $\begin{array}{l}\text { Versatile agent; increasing use; viability } \\
\text { detection validated against }{ }^{201} \mathrm{Tl} \text {, dobutamine } \\
\text { stress echocardiography, and PET }\end{array}$ \\
\hline${ }^{99 \mathrm{~m} T \mathrm{c} \text {-tetrofosmin }}$ & 6 hours & $800 \mathrm{MBq}$ & $8 \mathrm{mSv}$ & Not known & Nil & $\begin{array}{l}\text { Poorer extraction with vasodilator stress; } \\
\text { underestimates ischaemic burden; improved } \\
\text { extracardiac clearance suggested }\end{array}$ \\
\hline
\end{tabular}

Mbq, megabecquerel; mSv, millisievert; PET, positron emission tomography.

agents, and acquisition protocols. The resultant confusion has not furthered the cause of nuclear cardiology. Here we attempt to rationalise some of the methods used in the acquisition of myocardial perfusion images.

Patients are subjected to "stress" image acquisition after achieving peak stress in the conventional way (treadmill or bicycle), and they also undergo "rest" or "redistribution" image acquisition at a different time. The versatility of radiotracers allows different protocols to be used for evaluating myocardial viability, detecting reversible ischaemia, and simultaneously assessing perfusion and left ventricular function by gated SPECT.

Patients unable to achieve adequate treadmill stress undergo vasodilator stress with intravenous dipyridamole ${ }^{7}$ or adenosine. ${ }^{8}$ These vasodilator pharmacological stress studies are often combined with submaximal exercise which improves myocardial uptake, reduces liver and gut uptake of technetium-99m agents, and diminishes vasodilator side effects. ${ }^{9}$ This observation by Pennell and colleagues has now become widely used for both adenosine and dipyridamole protocols. Dobutamine is a commonly used alternative for patients with obstructive airways disease. The use of arbutamine has also been reported ${ }^{10}$ but its availability is restricted. New cardiospecific adenosine $\left(\mathrm{A}_{2 \mathrm{~A}}\right.$ receptor $)$ agonists are undergoing clinical evaluation and promise the specific induction of coronary hyperaemia. ${ }^{11}$

\section{RISK STRATIFICATION}

\section{The normal perfusion scan}

The prognostic value of thallium-201 is well established. ${ }^{12} \mathrm{~A}$ normal stress thallium-201 study has independent prognostic value. $^{13}$ A six year follow up study of normal thallium-201 perfusion studies (on 1137 patients) showed that the cardiac event rate (non-fatal myocardial infarction or cardiac death) was only $0.88 \% .{ }^{14}$ Recent studies have shown that, in the presence of a normal stress myocardial perfusion scan, exercise ECG had no added prognostic value. ${ }^{15}$

Technetium-99m sestamibi has been found to have a similar prognostic value. One of the problems with functional imaging has been poor specificity. The improvement in specificity with SPECT imaging is established, but technetium-99m sestamibi has clear advantages over thallium-201 SPECT, where gated sestamibi is better than non-gated. ${ }^{16}$ Table 2 shows the clear advantage of functional perfusion imaging - a normal scan is associated with a very low cardiac event rate. In 473 patients with chest pain, of whom $65 \%$ had an abnormal ST segment response to exercise, Soman and colleagues clearly showed the superior prognostic power of technetium-99m sestamibi, where normal scans were associated with an annual mortality of $0.2 \% .{ }^{17}$ Similarly a recent review of 14 trials including over 12000 patients with stable chest pain confirmed that normal technetium 99m-sestamibi SPECT is associated with a hard cardiac event rate of $0.6 \%$ per year. $^{18}$

\section{The abnormal perfusion scan}

As the myocardial perfusion scan represents global left ventricular perfusion, the size, severity, and reversibility of the defect implies the extent of risk, or the "total ischaemic burden". Similarly, a calculation of the number of segments involved on a multislice tomographic evaluation of the SPECT study can be used to calculate both the extent and severity of the ischaemic myocardium. Using sequential short axis slices, a polar map can be evaluated either visually or quantitatively to assess the total ischaemic burden. Figures 1 and 2 show a myocardial perfusion study from a patient with significant disease of the left anterior descending coronary artery. These polar and three dimensional quantitative images demonstrate the value of SPECT in predicting the extent, severity,

Table 2 The value of a normal myocardial perfusion scan

\begin{tabular}{|c|c|c|c|c|c|}
\hline Author & Radionuclide & Stress & $\begin{array}{l}\text { Number of } \\
\text { patients }\end{array}$ & Follow up (mean (SD)) & $\begin{array}{l}\text { Cardiac event } \\
\text { rate }\end{array}$ \\
\hline Wackers $1985^{51}$ & TI-201 & Exercise & 344 & 22 (3) months & 1 \\
\hline Wahl $1985^{13}$ & Tl-201 & Exercise & 455 & 14 months & 0.8 \\
\hline Steinberg $1993^{52}$ & TI-201 & Exercise & 309 & 10.3 years & 1 \\
\hline Brown $1994^{53}$ & $\mathrm{M} \mid \mathrm{BI}$ & $\begin{array}{l}\text { Exercise or } \\
\text { dipyridamole }\end{array}$ & 234 & 10 (3) months & 0.5 \\
\hline Stratmann $1994^{54}$ & MIBI & Exercise & 205 & $13(5)$ months & 0.5 \\
\hline Raiker $1994^{55}$ & $\mathrm{MIBI}$ & Exercise & 208 & $13.5(2.0)$ months & 0.5 \\
\hline Heller $1995^{56}$ & $\mathrm{MIB|}$ & Dipyridamole & 216 & $12.8(6.8)$ months & 1.4 \\
\hline Hachamovitch $1996^{15}$ & $\mathrm{MIBI} / \mathrm{Tl}-201$ & Exercise & 1623 & 566 (142) days & 0.3 \\
\hline Hachamovitch $1997^{8}$ & MlBI/TI-201 & Adenosine & 445 & 27.5 (9.1) months & 1.6 \\
\hline Soman $1999^{17}$ & $\mathrm{MIBI}$ & Exercise & 473 & 30 (16) months & 0.2 \\
\hline Groutas $2000^{57}$ & TETRO/TI-201 & $\begin{array}{l}\text { Exercise / } \\
\text { adenosine+exercise }\end{array}$ & 246 & 25 (3) months & 0.4 \\
\hline
\end{tabular}

Hard cardiac event rate with various radionuclide agents and stressors.

MIBI, technetium-99m sestamibi; TETRO, technetium- $99 \mathrm{~m}$ tetrofosmin. 


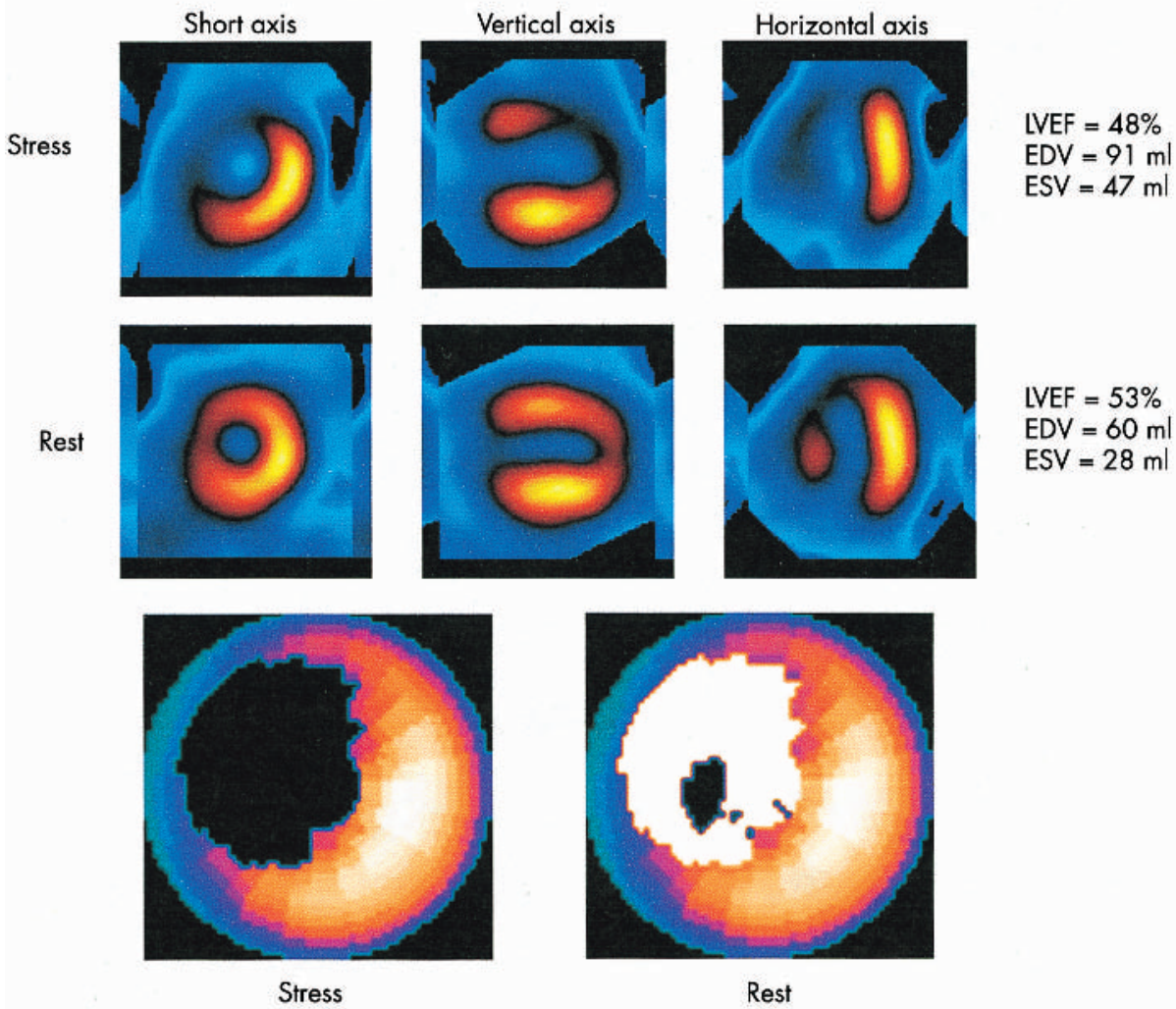

Figure 1 A 63 year old women with a previous anterior myocardial infarct presented with symptoms of dyspnoea and underwent a two day rest-stress technetium-99m sestamibi SPECT. The rest scan shows a small infarct in the antero-septal zone, but the stress scan shows reversible ischaemia with associated left ventricular dysfunction. This study indicates underlying viability and severe ischaemia and therefore represents a prognostically high risk study. A polar map or "bulls eye" is also shown. Blackout on the stress scan signifies total defect (infarct and ischaemia), while the white areas represent the amount of reversible ischaemia. EDV, end diastolic volume; ESV, end systolic volume; LVEF, left ventricular ejection fraction.

and reversibility of the perfusion defect-that is, the total ischaemic burden.

Though semiquantitative techniques work well, the ASNC guidelines are helpful for most departments. These use the short axis slices to evaluate the uptake in four broad quadrants (anterior, septal, inferior, and lateral). The left ventricle is further divided into apical, mid, and basal segments. The apex is assessed with the vertical long axis slice. The slices are divided into 17-20 segments. The uptake is scored in five grades: normal, mild, moderate, severe, or absent uptake. These techniques help standardisation between individuals and centres. Recently a consensus statement has been produced to bring together MPI, echocardiography, and other imaging modes. ${ }^{19}$

Well validated commercial quantitative programs are available on most gamma camera systems. The two most

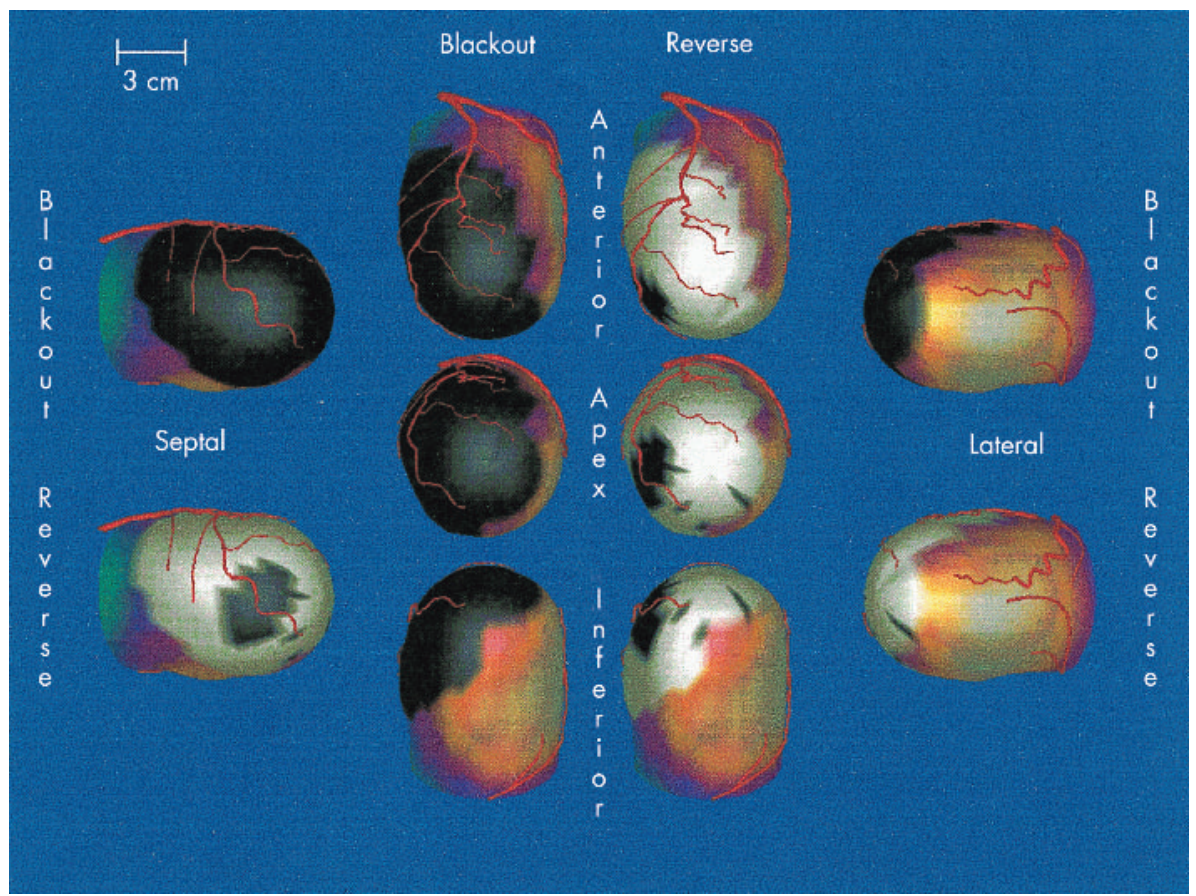

Figure 2 Three dimensional images from the same patient as in fig 1 , with a proximal stenosis of the left anterior descending coronary artery. These quantitative images represent the total ischaemic burden. A generic coronary tree has been overlaid in red. Images from Emory Cardiac Toolbox. ${ }^{21}$ 
commonly used are QPS/QGS ${ }^{20}$ and the Emory Cardiac Toolbox (ECTb). ${ }^{21}$ Both provide a quantitative estimate of the total ischaemic burden and left ventricular function. They employ complex algorithms and modelling, rather than relying on simple count based programs. Though the programs generally agree, a recent study has shown some inherent variation. ${ }^{22}$ For perfusion studies these programs employ a "normal" database, and therefore perfusion values falling outside the confidence limits are highlighted and the severity of the defect is computed (figs 1 and 2).

A representative method of scoring the total ischaemic burden is to calculate the "summed stress score" or SSS, using the method developed at Cedars-Sinai Hospital (Los Angeles, California, USA). ${ }^{23}$ In large studies (over 20000 patients) the SSS predicted patient outcome. A normal summed stress score (0-3) was associated with a mortality of less than $1 \%$, whereas an increasing SSS predicted higher cardiac mortality. ${ }^{15}$

Hachamovitch and colleagues evaluated the effects of medical treatment and revascularisation on mortality in patients stratified by the summed stress score. ${ }^{24}$ In lower risk scans (mildly abnormal; SSS 4-8), mortality was similar in both groups; thus there was no survival advantage for revascularisation. However, as the size of the defect increased (SSS $>9$ ) so the advantage with revascularisation showed an increased survival benefit (fig 3). This has important implications for the treatment provided and the costs associated with it.

How do the exercise ECG and functional imaging compare in current medical practice? The Duke treadmill score is a validated scoring system for identifying risk after a standard Bruce protocol ECG treadmill test. ${ }^{25}$ This score relies on exercise time, ST segment changes, and anginal symptoms. A high grade Duke treadmill score was considered to be associated with a good outcome, but it was originally not clear whether perfusion imaging would have any added value when the treadmill score was high. MPI and exercise ECGs were done in 2203 patients who were stratified by low, intermediate, and high likelihood of significant coronary artery disease using history, examination, exercise ECG, and Duke treadmill score. MPI provided additional incremental prognostic value irrespective of the Duke treadmill score result (fig 4$).^{15}$

Other factors identified with MPI that are associated with a worse long term prognosis are evidence of multiple defects,

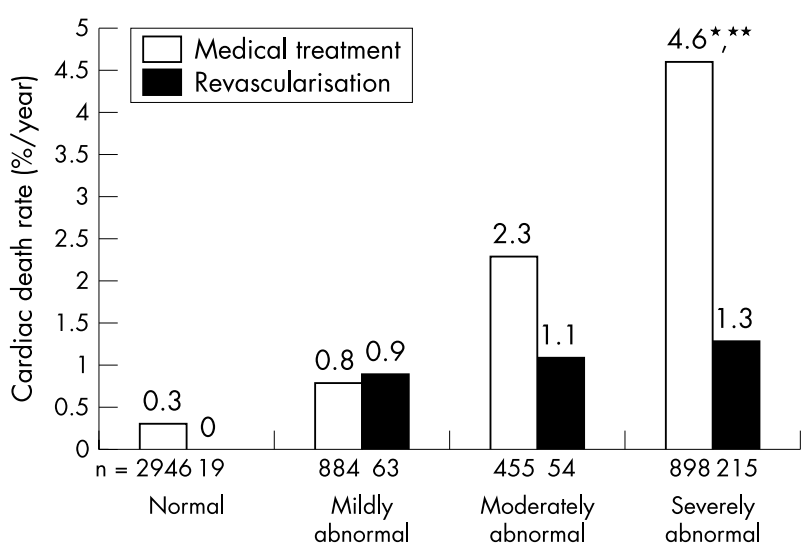

Figure 3 Rates of cardiac death per year as a function of scan result and type of treatment. Black bars represent patients undergoing medical treatment after SPECT; white bars represent patients undergoing revascularisation after SPECT. * $p<0.01 v$ patients undergoing revascularisation early after SPECT; ${ }^{* *} \mathrm{p}<0.001$ within patients undergoing revascularisation early after SPECT. ${ }^{24}$ left ventricular chamber dilatation post-exercise, and increased lung uptake with thallium-201.

These quantitative methods are also effective in a clinical trial where technetium-99m sestamibi was compared with technetium-99m tetrofosmin. ${ }^{26}$ This study using total ischaemic burden calculated by quantitative methods showed that tetrofosmin underestimated the extent of ischaemia in patients with known coronary artery disease. This may reflect the lower myocardial extraction fraction of technetium-99m tetrofosmin and has obvious clinical implications.

\section{GATED SPECT: SIMULTANEOUS MEASUREMENT OF MYOCARDIAL PERFUSION AND FUNCTION}

Gated SPECT has made a fundamental change in perfusion imaging by allowing clearer identification of attenuation artefacts (breast and diaphragm), cine visualisation of left ventricular wall thickening (flow/function relation), and accurate estimation of left ventricular ejection fraction and left ventricular volumes. The high photon flux and lack of redistribution of technetium-99m sestamibi clearly has an advantage over thallium-201. Owing to the higher count rate with technetium-99m agents there has been a considerable improvement in spatial and temporal resolution, thus allowing improved sensitivity and specificity for technetium-99m sestamibi ${ }^{27}$ or tetrofosmin ${ }^{28}{ }^{29}$ over thallium-201.

Taillefer and colleagues compared the specificity of thallium-201, technetium-99m sestamibi, and ECG gated technetium-99m sestamibi SPECT in women. ${ }^{16}$ The specificity for thallium-201 SPECT was $67.2 \%$, technetium-99m sestamibi SPECT $84.4 \%$, and ECG gated technetium-99m sestamibi SPECT $92.2 \%$. Others have confirmed the value of gated SPECT in decreasing the number of non-diagnostic studies. ${ }^{30}$ In a recent study of patients with acute chest pain and nonST-segment elevation, Swinburn and colleagues found that gated sestamibi SPECT abnormalities were highly indicative of a poor outcome when compared with markers of necrosis and inflammation. ${ }^{31}$

\section{Post-exercise "stunning"}

Recent observations have shown significant left ventricular chamber dilatation or wall thickening abnormality following delayed post-exercise imaging with thallium-201, or in particular, technetium-99m sestamibi SPECT studies, 30-90 minutes after cessation of exercise. ${ }^{32-35}$ This phenomenon is thought to reflect post-ischaemic stunning or extensive subendocardial ischaemia. As technetium-99m sestamibi acts as a "microsphere", the perfusion is "frozen" at the time of injection, but wall thickening changes reflect real time events at the time of imaging rather than at injection.

A seminal study by Sharir and colleagues has shown the value of assessing simultaneous perfusion and function from post-stress gated SPECT using the QGS program (fig 5). ${ }^{36}$ Addition of end systolic volume (ESV $>70 \mathrm{ml}$ ) to left ventricular ejection fraction (LVEF $<45 \%$ ) clearly improved

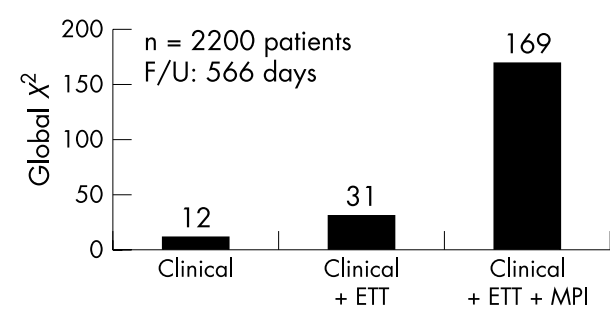

Figure 4 A multivariate Cox proportional hazards model for incremental prognostic value between clinical history, examination, exercise ECG, and nuclear imaging. ${ }^{15} \mathrm{ETT}$, exercise ECG; MPI, myocardial perfusion imaging. 


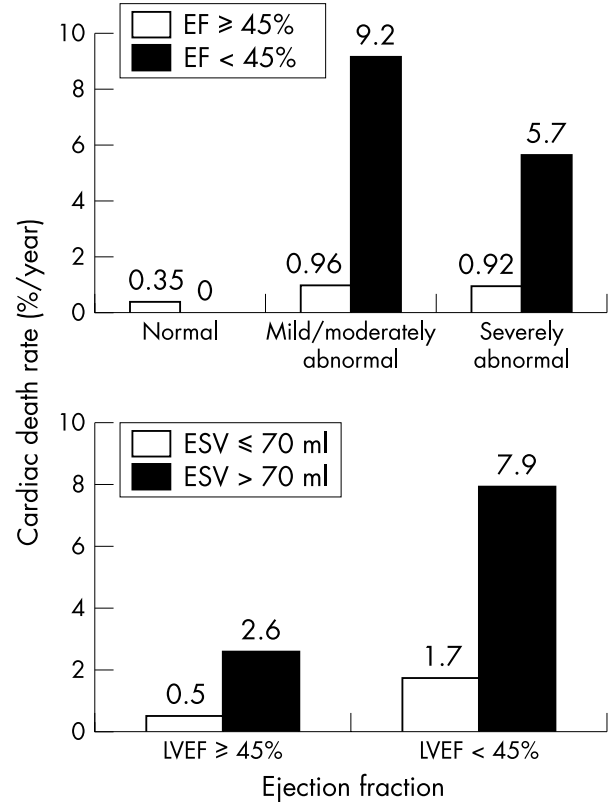

Figure 5 The prognostic value of post-stress left ventricular ejection fraction (LVEF) by gated SPECT. The addition of a reduced LVEF increases the risk of cardiac death irrespective of the perfusion data. The addition of end systolic volume data (ESV) further increases the diagnostic potential of gated SPECT. ${ }^{36}$

the prognostic value of subsequent cardiac risk, over and above that of perfusion abnormalities alone.

\section{PERFUSION IMAGING IN PATIENTS WITH LEFT VENTRICULAR DYSFUNCTION}

Heart failure is rapidly becoming a significant burden on health resources. Also, the challenge of heart failure caused by ischaemic cardiomyopathy has serious economic implications. As a result there has been much interest in the use of perfusion ligands for detecting viable myocardium in potentially recoverable but severely dysfunctional myocardium (hibernating myocardium).

The CASS study first highlighted the benefit of revascularisation in patients with left ventricular dysfunction. ${ }^{37}$ However, recent studies have shown that reduced myocardial viability is associated with an increased mortality after revascularisation; thus the demonstration of myocardial viability is crucial in determining the prognosis after revascularisation. ${ }^{38-40}$

There are many techniques available for determining myocardial viability. Thallium-201 and technetium-99m sestamibi have both been validated ${ }^{41}$ and compare favourably with positron emission tomography (PET) and dobutamine echocardiography. ${ }^{42}{ }^{43}$ Thallium-201 reveals myocyte viability by assessing the integrity of the sodium-potassium ATPase pathway, which requires an intact myocyte cell membrane. Sestamibi is taken up by the mitochondria within the cell, and thus demonstrates an intact myocyte.

Recently, Senior et al have shown that nitrate enhanced technetium-99m sestamibi SPECT is similar to dobutamine echocardiography (which reveals contractile reserve) and also to thallium-201 for determining myocardial viability. ${ }^{44}$ Siebelink et al also found that technetium-99m sestamibi SPECT was similar to FDG-PET imaging for detecting viability. ${ }^{45}$

Recent studies by Senior et al and Kitsiou et al have demonstrated that painless myocardial ischaemia is a common finding of ischaemic cardiomyopathy. ${ }^{44}{ }^{46}$ Its presence predicts viable myocardium and greater recovery of function after revascularisation. ${ }^{47}$ Thus, as ischaemia probably plays an important role in the genesis of repeated stunning or hibernation and therefore in further deterioration of left ventricular function, it was hypothesised that carvedilol, with its multiple actions, might improve hibernating myocardium (the CHRISTMAS trial: carvedilol hibernation reversible ischaemia trial: marker of success). This study has recently been reported and shows that both reversible ischaemia and myocardial viability are common features of ischaemic cardiomyopathy and heart failure. ${ }^{48}$ Carvedilol improved left ventricular function in both groups (with or without hibernation); however, it had a greater impact on patients with reversible ischaemia. The HEART-UK trial will set out to evaluate whether patients with myocardial viability have a better outcome after revascularisation than with maximum medical treatment.

Patients with severely impaired left ventricular systolic function and viability have a poor prognosis. The restoration of function either by revascularisation or by pharmacological means improves outcome. The ability to select patients with a standard SPECT protocol is obviously beneficial as this has prognostic and economic implications.

\section{COST ECONOMICS}

In the new climate of cost containment there has been some attempt to estimate the economic cost associated with MPI. The END (economics of noninvasive diagnosis) study ${ }^{49}$ compared direct cardiac catheterisation with MPI followed by selective cardiac catheterisation to diagnose coronary artery disease in specialist cardiology centres in the USA. None of the patients underwent risk stratification with the standard exercise ECG. Diagnostic and follow up costs were lower when a strategy employing MPI before selective cardiac catheterisation was used. The cardiac deaths and non-fatal myocardial infarction rates were slightly lower in the MPI arm than in the direct catheterisation arm, at $2.8 \%$ and $2.8 \% \mathrm{v}$ $3.3 \%$ and $3.0 \%$, respectively $(\mathrm{p}=\mathrm{ns}$ ) (table 3 ). The EMPIRE (economics of myocardial perfusion imaging in Europe) study ${ }^{50}$ compared 396 patient records from eight hospitals in four European countries. Retrospective analysis on suitable patients was done to compare four different strategies used to diagnose coronary artery disease. The results suggested that a

Table 3 Data adapted from the END (economics of noninvasive diagnosis) study ${ }^{49}$ comparing two strategies for diagnosing coronary artery disease

\begin{tabular}{lll}
\hline Cost parameters & MPI (n=5826) & $\begin{array}{l}\text { Catheterisation } \\
(\mathbf{n}=5423)\end{array}$ \\
\hline $\begin{array}{l}\text { Rate of normal cardiac } \\
\text { catheterisation }\end{array}$ & $33 \%$ & $43 \%$ \\
$\begin{array}{l}\text { Revascularisation } \\
\text { LR }\end{array}$ & $14 \%$ & $16 \%$ \\
IR & $13 \%$ & $27 \%$ \\
HR & $16 \%$ & $30 \%$ \\
Cardiac death rate & $2.8 \%$ & $3.3 \%$ \\
Cost per patient (\$US) & $\$ 2000$ & $\$ 2900$ \\
LR & $\$ 2400$ & $\$ 4200$ \\
IR & $\$ 2800$ & $\$ 4800$ \\
HR & & \\
\hline
\end{tabular}

The first column represents myocardial perfusion imaging before cardiac catheterisation. The second column represents patients going directly to cardiac catheterisation without any functional testing. The data for revascularisation and cost are stratified according to pre-test likelihood of coronary artery disease. ${ }^{4}$

Catheterisation, direct cardiac catheterisation; HR, high pre-test likelihood of coronary artery disease; IR, intermediate pre-test likelihood of coronary artery disease; $L R$, low pre-test likelihood of coronary artery disease; MPI, myocardial perfusion imaging (followed by selective cardiac catheterisation). 
strategy using MPI was economically efficient without any effect on the outcome for the patient.

\section{CONCLUSIONS}

Myocardial perfusion imaging is a useful adjunct to the noninvasive assessment of patients with stable angina, baseline ECG abnormalities, post-revascularisation assessment, and heart failure, and in those unable to exercise.

Functional imaging is clearly superior to standard exercise testing when used to diagnose coronary artery disease. The degree of severity shown on the scan reveals the likelihood of further cardiac event rates. This is independent of the patient's history, examination, resting ECG, and stress ECG result. The identification of myocardial viability in heart failure by gated SPECT is of paramount importance for the long term management of the patient. The use of these new functional tests will help our modern health systems to allocate resources judiciously, which will result in improved patient management and a sound economic structure.

MPI has an exciting future. There are significant developments emerging with regard to new isotopes, imaging protocols, software, and hardware. The new isotopes are aimed not only at myocardial perfusion but also at viability imaging, apoptosis and cell death, sympathetic receptor imaging, hypoxia, atherosclerotic plaque stability, and cellular metabolism. Acute chest pain evaluation with SPECT in the emergency room is emerging as a useful and rapid tool for risk stratification in patients awaiting serum troponin estimation. Enhanced computer processing, faster networks, and sophisticated software will allow images to be collected at peripheral sites and interpreted at specialised regional centres, thus allowing the technique to be disseminated without loss of expertise.

\section{Authors' affiliations}

N K Sabharwal, A Lahiri, Department of Cardiac Research, Northwick Park Hospital, Harrow, Middlesex, UK

\section{REFERENCES}

1 Pryor DB, Harrell FEJ, Lee KL, et al. Estimating the likelihood of significant coronary artery disease. Am J Med 1983;75:771-80.

2 Diamond GA, Forrester JS. Analysis of probability as an aid in the clinical diagnosis of coronary-artery disease. N Engl J Med 1979;300:1350-8.

3 Detrano R, Gianrossi R, Froelicher V. The diagnostic accuracy of the exercise electrocardiogram: a meta-analysis of 22 years of research. Prog Cardiovasc Dis 1989;32:173-206.

4 Gibbons RJ, Hodge DO, Berman DS, et al. Long-term outcome of patients with intermediate-risk exercise electrocardiograms who do not have myocardial perfusion defects on radionuclide imaging. Circulation 1999:100:2140-5.

5 Marwick TH, Case C, Sawada S, et al. Prediction of mortality using dobutamine echocardiography. J Am Coll Cardiol 2001;37:754-60.

6 Marwick TH, Case C, Vasey C, et al. Prediction of mortality by exercise echocardiography: a strategy for combination with the duke treadmill score. Circulation 2001:103:2566-71.

7 Stratmann HG, Tamesis BR, Younis LT, et al. Prognostic value of dipyridamole technetium- $99 \mathrm{~m}$ sestamibi myocardial tomography in patients with stable chest pain who are unable to exercise. Am J Cardiol 1994;73:647-52.

8 Hachamovitch R, Berman DS, Kiat $\mathrm{H}$, et al. Incremental prognostic value of adenosine stress myocardial perfusion single-photon emission computed tomography and impact on subsequent management in patients with or suspected of having myocardial ischemia. Am J Cardiol 1997;80:426-33.

9 Pennell DJ, Mavrogeni Sl, Forbat SM, et al. Adenosine combined with dynamic exercise for myocardial perfusion imaging. J Am Coll Cardiol 1995; 25:1300-9.

10 Khattar RS, Senior R, Joseph D, et al. Comparison of arbutamine stress $99 \mathrm{mT}$-labeled sestamibi single-photon emission computed tomographic imaging and echocardiography for detection of the extent and severity of coronary artery disease and inducible ischemia. I Nucl Cardiol 1997:4:211-16.

11 Glover DK, Ruiz M, Yang JY, et al. Pharmacological stress thallium scintigraphy with 2-cyclohexylmethylidenehydrazinoadenosine (WRC-0470). A novel, short-acting adenosine A2A receptor agonist. Circulation 1996;94:1726-32.

12 Brown KA. Prognostic value of thallium-201 myocardial perfusion imaging. A diagnostic tool comes of age. Circulation 1991;83:363-81.

13 Wahl JM, Hakki AH, Iskandrian AS. Prognostic implications of normal exercise thallium 201 images. Arch Intern Med 1985;145:253-6.
14 Vanzetto G, Ormezzano O, Fagret D, et al. Long-term additive prognostic value of thallium-201 myocardial perfusion imaging over clinical and exercise stress test in low to intermediate risk patients: study in 1137 patients with 6-year follow-up. Circulation 1999:100:1521-7.

15 Hachamovitch R, Berman DS, Kiat $\mathrm{H}$, et al. Exercise myocardial perfusion SPECT in patients without known coronary artery disease: incremental prognostic value and use in risk stratification. Circulation 1996:93:905-14.

16 Taillefer R, DePuey EG, Udelson JE, et al. Comparative diagnostic accuracy of TI-201 and Tc-99m sestamibi SPECT imaging (perfusion and ECG-gated SPECT) in detecting coronary artery disease in women. J Am Coll Cardiol 1997:29:69-77.

17 Soman P, Parsons A, Lahiri N, et al. The prognostic value of a normal Tc- $99 \mathrm{~m}$ sestamibi SPECT study in suspected coronary artery disease. I Nucl Cardiol 1999;6:252-6.

18 Iskander S, Iskandrian AE. Risk assessment using single-photon emission computed tomographic technetium-99m sestamibi imaging. J Am Coll Cardiol 1998;32:57-62.

19 Cerqueira MD, Weissman NJ, Dilsizian V, et al. Standardized myocardial segmentation and nomenclature for tomographic imaging of the heart: a statement for healthcare professionals from the cardiac imaging committee of the Council on Clinical Cardiology of the American Heart Association. J Nucl Cardiol 2002;9:240-5

20 Germano G, Kiat H, Kavanagh PB, et al. Automatic quantification of ejection fraction from gated myocardial perfusion SPECT. J Nucl Med 1995; 36:2138-47.

21 Faber TL, Cooke CD, Folks RD, et al. Left ventricular function and perfusion from gated SPECT perfusion images: an integrated method. J Nucl Med 1999:40:650-9.

22 Nichols K, Santana CA, Folks R, et al. Comparison between ECTb and QGS for assessment of left ventricular function from gated myocardial perfusion SPECT. J Nucl Cardiol 2002:9:285-93.

23 Berman D, Hachamovitch R, Lewin $\mathrm{H}$, et al. Risk stratification in coronary artery disease: implications for stabilization and prevention. Am J Cardiol 1997;79:10-16.

24 Hachamovitch R, Berman DS, Shaw $\sqcup$, et al. Incremental prognostic value of myocardial perfusion single photon emission computed tomography for the prediction of cardiac death: differential stratification for risk of cardiac death and myocardial infarction [Published erratum appears in Circulation 1998:98:190]. Circulation 1998;97:535-43.

25 Mark DB, Shaw L, Harrell FEJ, et al. Prognostic value of a treadmill exercise score in outpatients with suspected coronary artery disease. N Engl J Med 1991;325:849-53.

26 Soman P, Taillefer R, DePuey EG, et al. Enhanced detection of reversible perfusion defects by Tc-99m sestamibi compared to Tc- $99 \mathrm{~m}$ tetrofosmin during vasodilator stress SPECT imaging in mild-to-moderate coronary artery disease. J Am Coll Cardiol 2001;37:458-62.

27 Berman DS, Kiat H, Van Train KF, et al. Comparison of SPECT using technetium-99m agents and thallium-201 and PET for the assessment of myocardial perfusion and viability. Am J Cardiol 1990;66:72-9E.

28 Sridhara BS, Braat $S$, Rigo $P$, et al. Comparison of myocardial perfusion imaging with technetium-99m tetrofosmin versus thallium-201 in coronary artery disease. Am J Cardiol 1993:72:1015-19.

29 Zaret BL, Rigo P, Wackers FJ, et al. Myocardial perfusion imaging with $99 \mathrm{mTc}$ tetrofosmin. Comparison to 201Tl imaging and coronary angiography in a phase III multicenter trial. Tetrofosmin international trial study group. Circulation 1995:91:313-19.

30 Smanio PE, Watson DD, Segalla DL, et al. Value of gating of technetium- $99 \mathrm{~m}$ sestamibi single-photon emission computed tomographic imaging. J Am Coll Cardiol 1997:30:1687-92.

31 Swinburn JMA, Stubbs P, Soman P, et al. Rapid assessment of patients with nonST-segment elevation acute chest pain: troponins, inflammatory markers, or perfusion imaging? J Nucl Cardiol 2002;9:491-9.

32 Chouraqui P, Rodrigues EA, Berman DS, et al. Significance of dipyridamole-induced transient dilation of the left ventricle during thallium-201 scintigraphy in suspected coronary artery disease. Am J Cardiol 1990;66:689-94

33 Borges-Neto S, Javaid A, Shaw LK, et al. Poststress measurements of left ventricular function with gated perfusion SPECT: comparison with resting measurements by using a same-day perfusion-function protocol. Radiology 2000;215:529-33

34 Johnson LL, Verdesca SA, Aude WY, et al. Postischemic stunning can affect left ventricular ejection fraction and regional wall motion on post-stress gated sestamibi tomograms. J Am Coll Cardiol 1997;30:1641-8.

35 Otto AC, van Staden J, van Aardt A, et al. Evaluation of exercise-induced stunning using myocardial perfusion imaging. Cardiovasc J Southern Africa 2001:12:259-62.

36 Sharir T, Germano G, Kavanagh PB, et al. Incremental prognostic value of post-stress left ventricular ejection fraction and volume by gated myocardial perfusion single photon emission computed tomography. Circulation 1999:100:1035-42.

37 Alderman EL, Fisher LD, Litwin P, et al. Results of coronary artery surgery in patients with poor left ventricular function (CASS). Circulation 1983:68.785-95.

38 Pagley PR, Beller GA, Watson DD, et al. Improved outcome after coronary bypass surgery in patients with ischemic cardiomyopathy and residual myocardial viability. Circulation 1997;96:793-800.

39 Beller GA. Assessment of myocardial viability. Curr Opin Cardiol 1997:12:459-67. 
40 Senior R, Kaul S, Lahiri A. Myocardial viability on echocardiography predicts long-term survival after revascularization in patients with ischemic congestive heart failure. J Am Coll Cardiol 1999;33:1848-54.

41 Sansoy V, Glover DK, Watson DD, et al. Comparison of thallium-201 resting redistribution with technetium- $99 \mathrm{~m}$-sestamibi uptake and functional response to dobutamine for assessment of myocardial viability. Circulation 1995;92:994-1004

42 Marzullo P, Parodi O, Reisenhofer B, et al. Value of rest thallium-201/ technetium $-99 \mathrm{~m}$ sestamibi scans and dobutamine echocardiography for detecting myocardial viability. Am J Cardiol 1993;71:166-72.

43 Sawada SG, Allman KC, Muzik O, et al. Positron emission tomography detects evidence of viability in rest technetium- $99 \mathrm{~m}$ sestamibi defects. J Am Coll Cardiol 1994;23:92-8.

44 Senior R, Kaul S, Raval U, et al. Impact of revascularisation and myocardial viability determined by nitrate enhanced technetium $-99 \mathrm{~m}$ sestamibi and thallium-201 imaging on mortality and functional outcome in ischaemic cardiomyopathy. J Nucl Cardiol 2002;9:454-62.

45 Siebelink HM, Blanksma PK, Crijns HJ, et al. No difference in cardiac eventfree survival between positron emission tomography-guided and singlephoton emission computed tomography-guided patient management: a prospective, randomized comparison of patients with suspicion of jeopardized myocardium. J Am Coll Cardiol 2001;37:81-8.

46 Kitsiou AN, Srinivasan G Quyyumi AA, et al. Stress-induced reversible and mild-to-moderate irreversible thallium defects: are they equally accurate for predicting recovery of regional left ventricular function after revascularization? Circulation 1998;98:501-8.

47 Lahiri A. The role of cardiac imaging in optimizing therapy in heart failure [letter; comment]. J Nucl Cardiol 2000;7:81-4.

48 Cleland JG, Pennell DJ, Ray SG, et al. The Carvedilol Hibernation Reversible Ischaemia Trial: Marker of Success (CHRISTMAS) [abstract]. J Am Coll Cardiol 2002;39(suppl 5A):172A.
49 Shaw L, Hachamovitch R, Berman DS, et al. The economic conseguences of available diagnostic and prognostic strategies for the evaluation of stable angina patients: an observational assessment of the value of precatheterization ischemia. Economics of Noninvasive Diagnosis (END) Multicenter Study Group. J Am Coll Cardiol 1999:33:661-9.

50 Underwood SR, Godman B, Salyani S, et al. Economics of myocardial perfusion imaging in Europe-the EMPIRE study. Eur Heart $J$ 1999;20:157-66

51 Wackers FJ, Russo DJ, Russo D, et al. Prognostic significance of normal quantitative planar thallium-201 stress scintigraphy in patients with chest pain. J Am Coll Cardiol 1985;6:27-30.

52 Steinberg EH, Koss JH, Lee M, et al. Prognostic significance from 10-year follow-up of a qualitatively normal planar exercise thallium test in suspected coronary artery disease. Am J Cardiol 1993:71:1270-3.

53 Brown KA, Altland E, Rowen M. Prognostic value of normal technetium- $99 \mathrm{~m}$ sestamibi cardiac imaging. J Nucl Med 1994;35:554-7.

54 Stratmann HG, Williams GA, Wittry MD, et al. Exercise technetium-99m sestamibi tomography for cardiac risk stratification of patients with stable chest pain. Circulation 1994:89:615-22.

55 Raiker K, Sinusas AJ, Wackers FJ, et al. One-year prognosis of patients with normal planar or single-photon emission computed tomographic technetium $99 \mathrm{~m}$-labeled sestamibi exercise imaging. J Nucl Cardiol 1994:1:449-56.

56 Heller GV, Herman SD, Travin MI, et al. Independent prognostic value of intravenous dipyridamole with technetium-99m sestamibi tomographic imaging in predicting cardiac events and cardiac-related hospital admissions. J Am Coll Cardiol 1995;26:1202-8.

57 Groutars RG, Verziilbergen JF, Muller AJ, et al. Prognostic value and quality of life in patients with normal rest thallium-201/stress technetium $99 \mathrm{~m}$-tetrofosmin dual-isotope myocardial SPECT. J Nucl Cardiol 2000; $7: 333-41$.

\section{IMAGES IN CARDIOLOGY}

\section{Improved detection of protruding apical thrombus with contrast echocardiography}

A 68 year old man with a history of anterior myocardial infarction, congestive heart failure, and hypertension was referred for transthoracic echocardiography to evaluate left ventricular function. Tissue harmonic imaging of the apical four chamber view revealed inadequate endocardial definition of all myocardial segments, including the apex (below left). Therefore, images were repeated during intravenous octafluoropropane (Optison) injection. A $2 \mathrm{~cm}$ diameter protruding thrombus was visualised as a non-enhanced, spherical structure at the left

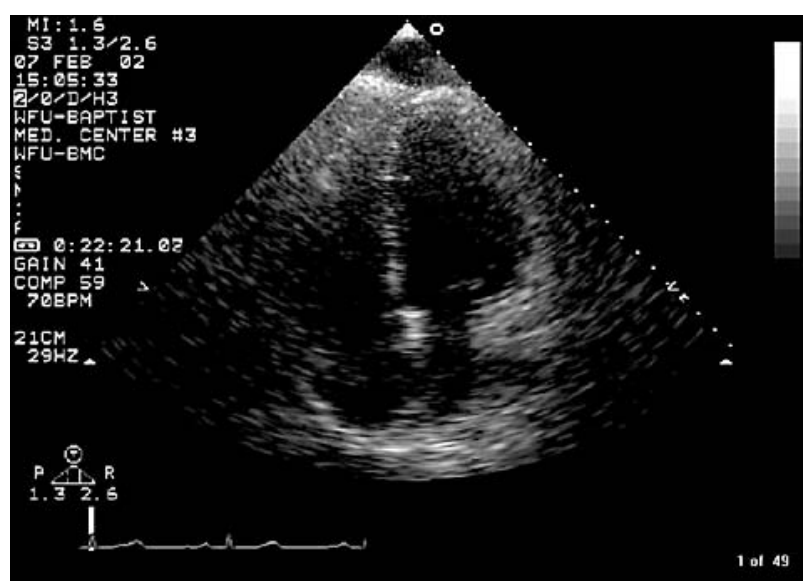

ventricular apex (below right, arrowheads indicate protruding thrombus). This case illustrates the utility of contrast echocardiography to improve detection of apical thrombus in patients who have inadequate images from routine echocardiographic examination.

P Rerkpattanapipat

C Brown

D W Kitzman

prerkpat@wfubmc.edu

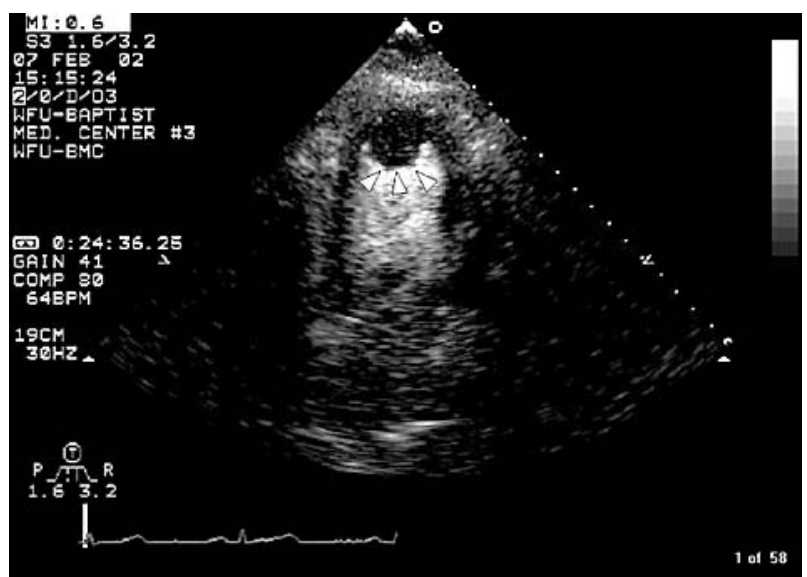

